\title{
The effects of major genes on quantitatively varying characters in barley 1. The GP ert locus
}

\author{
W. Powell, $\dagger$ \\ W. T. B. Thomas, $\dagger$ \\ P. D. S. Caligari $\dagger$ and \\ J. L. Jinks*
}

\author{
$\uparrow$ Scottish Crop Research Institute, Pentlandfield, \\ Roslin, Midlothian, EH25 9RF, U.K. \\ * Genetics Department, University of Birmingham, \\ Birmingham, B15 2TT, U.K.
}

\begin{abstract}
Random inbred lines produced by doubled haploidy and single seed descent have been used to examine the effect of the GP ert locus on quantitatively varying characters in spring barley. In general the mean of the erectoides sub-population is lower than that of the corresponding nutans sub-population for characters such as thousand grain weight, main stem weight and single plant yield. Furthermore, allelic variation at the GP ert locus makes a large contribution to the additive genetic variation for a number of characters. A suitable strategy for the deployment of dwarfing genes in barley breeding programmes is discussed.
\end{abstract}

\section{INTRODUCTION}

During the past 30 years, barley breeders have endeavoured to produce short, stiff strawed varieties that respond to the use of nitrogenous fertilizers without lodging in adverse weather conditions. A large number of dwarfing genes have been identified and used in barley breeding programmes to produce lines resistant to lodging. One of the most commonly used types of short straw in European spring barleys is that associated with an erect juvenile growth habit and erect ear carriage. Sources of this gene include the semi-dwarf variety Golden Promise which is a gamma ray mutant of the variety Maythorpe. This variety has been widely grown in Scotland and the erectoides dwarfing gene has often been used in the SCRI spring barley breeding programme.

The dwarfing gene present in Golden Promise has been shown to be a recessive major gene (GP ert) and is located on the short arm of chromosome 7 (Thomas, Powell and Wood, 1984). Unfortunately the effects of this particular dwarfing gene on agronomic characters have usually been evaluated in varietal comparisons where the effects of the dwarfing gene are confounded with other genetic factors. Hence the effects of this gene on quantitative characters and the consequences of its use in breeding programmes have not been fully explored. The best way to evaluate the effects of the dwarfing gene is to compare random inbred lines which can be classified for the alternative allele at the gene locus of interest. In this way the background genetic effect will be nullified. Random inbred lines have been produced by doubled haploidy from $F_{1}$ plants heterozygous for the erectoides gene in conjunction with single seed descent lines to investigate the relationship between the erectoides dwarfing gene and characters of agronomic importance.

\section{MATERIALS AND METHODS}

\section{(a) The material studied}

As part of a series of experiments conducted with the Genetics Department of the University of Birmingham, doubled haploids $(\mathrm{DH})$, produced by the Hordeum bulbosum technique, and single seed descent (SSD) lines were generated from the following crosses:

Golden Promise $\times$ Mazurka (TT1)

Golden Promise $\times$ Ark Royal (TT3)

BH4/143/2 × Ark Royal (TT4) 
Details of the experimental techniques used in deriving the material can be found in Huang, Dunwell, Powell, Hayter and Wood (1984) and Thomas and Tapsell (1983). Twenty DH lines were produced from the $F$, hybrids in the 3 crosses and 90 SSD lines were produced from $F_{2}$ seeds. In addition, $56 \mathrm{DH}$ lines were produced from random $F_{2}$ plants in the TT4 cross.

\section{(b) The experiment}

\section{(i) The drilled experiment}

The 90 random SSD lines from each of the 3 crosses were advanced to the $\mathrm{F} 4$ generation and then multiplied before assessment at the F6 generation. This material was grown, together with 10 control varieties, in 1979 in a two replicate generalized lattice small plot yield trial at the Murrays Farm, East Lothian.

\section{(ii) The spaced plant experiment}

The $F_{1}$ and $F_{2}$ derived DH lines were grown together with 40 SSD lines in a replicated experiment in 1983, again at the Murrays Farm, East Lothian. The experimental design was a randomised complete block of two replicates. Single plants were spaced $5 \mathrm{~cm}$ apart within rows and $22.5 \mathrm{~cm}$ apart between rows. The experiment was netted to prevent bird damage.

\section{(c) The characters}

The material was scored for juvenile growth habit approximately 6 weeks after sowing. It was therefore possible to classify the inbred lines into two groups: an erect group which possessed the erectoides dwarfing allele and the tall (nutans) group which possessed the corresponding nutans allele. During the growing season the following characters were scored:

(a) Awn emergence, scored as days from 1st June until awns emerged from the flag leaf sheath of the main stem (AL).

(b) Ear emergence, scored as days from 1st June until ears fully emcrged from the flag leaf sheath of the main stem (EE).

(c) Maturity, scored on a 1 to 9 scale with 1 -early, 9-late (Mat).

(d) Lodging, scored on the drilled experiment on a 1 to 9 scalc with 9 representing a completely lodged plot (Lod).

After harvest, sheaves were returned to the laboratory and 5 plants were chosen at random for experiment (ii). For experiment (i) five plants were taken at random from each plot before it was harvested with a small plot combine. The experiments were scored for different sub-sets of the following characters:

(e) Final height, measured from the base of the plant to the collar in $\mathrm{cm}$. (Ht).

(f) The number of fertile tillers per plant (TN).

(g) The number of grains per ears on the main stem (GN).

(h) The yield of grain on the main stem (MSW).

(i) The length of the ear on the main stem (EL).

(j) Thousand grain weight (TGW) calculated from $(\mathrm{g})$ and $(\mathrm{h})$.

(k) Grain yield of the whole plant, single plant yield (SPY).

(1) Neck length, measured in $\mathrm{cm}$ from the flag leaf auricles to the collar of the main stem (NL).

(m) Bulk yield was measured on the drilled experiment in $\mathrm{g} \mathrm{m}^{2}(\mathrm{BY})$.

\section{RESULTS}

\section{(i) Drilled plot experiment}

The results from the analyses of variance for the three populations (TT1, TT3 and TT4) observed under drilled plot conditions and segregating for alleles at the GP ert locus are given in table 1. There were significant differences between lines in the TTl cross for: height, neck length, lodging, awn emergence, ear emergence, main stem weight, thousand grain weight, single piant yield and bulk yield. With the exception of main stem weight, tiller number and single plant yield in the TT3 cross, all the other variates scored in both the TT3 and TT4 crosses displayed significant variation. The fact that the mean square between lines was significant when tested against the error term indicated that there was significant additive genetic variation $(D)$ for those characters. The magnitude of this variation can be calculated from the expected mean squares for the experiment since the between line component $\left(\sigma_{I}^{2}\right)$ will give a measure of ${ }_{8}^{7} \mathrm{D}$.

The main item of interest is the comparison between the erectoides and nutans populations. Although there were small differences between the three crosses, in general there were significant differences between the sub-populations for the majority of characters scored. By classifying the inbred lines into the two groups carrying the alternative allele, it is possible to assess the effects of the GP ert locus on mean performance in a random genetic background. The mean scores for the nutans and erectoides groups are given in table 2. It should be noted that for a number of characters such as thousand grain weight the mean of 
Table 1 Analyses of variance for the 3 SSD populations derived from TT1, TT3 and TT4

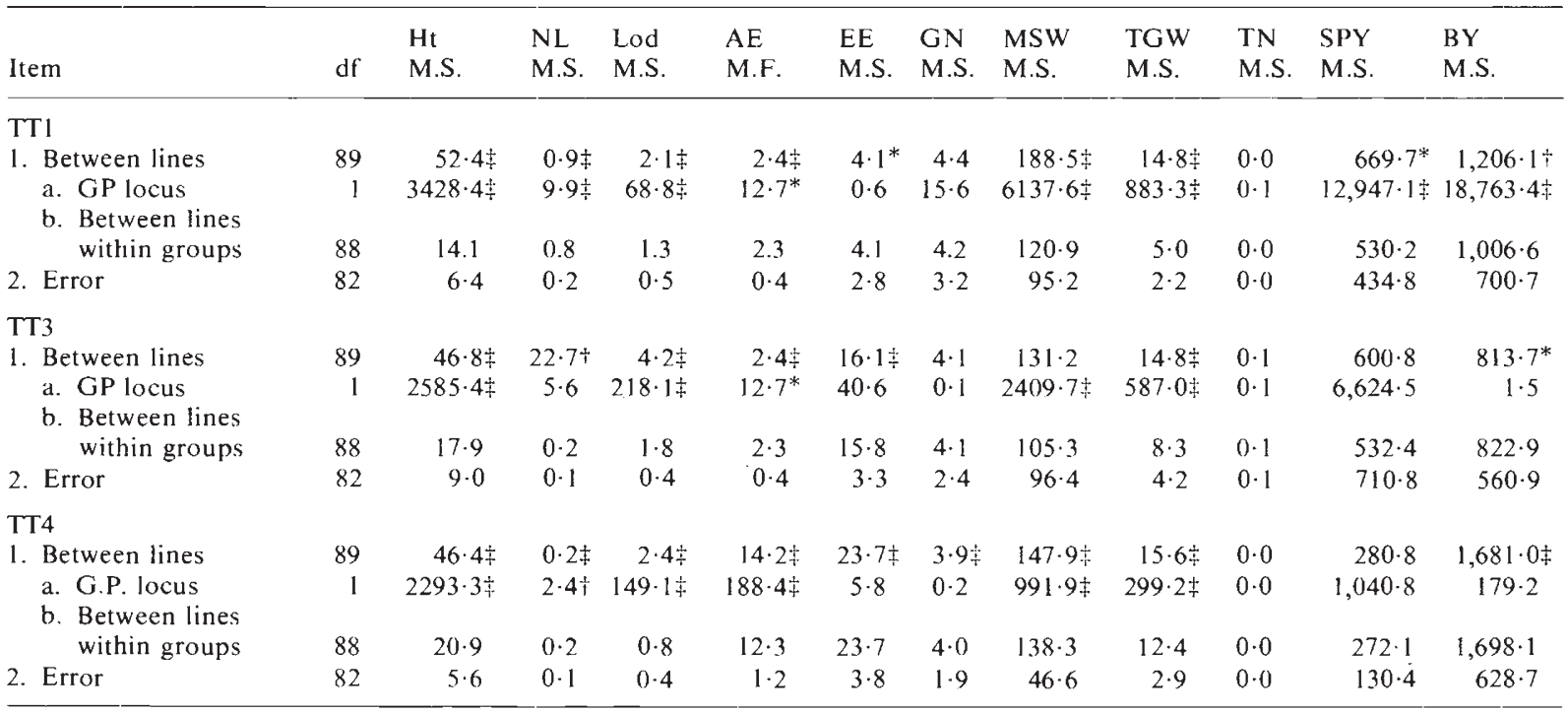

$* \mathrm{P}=0.05, \div \mathrm{P}=0 \cdot 01, \doteqdot \mathrm{P}=0.001$

Table 2 Means and ranges for the parents and sub-populations produced from TT1, TT3 and TT4 by SSD

\begin{tabular}{|c|c|c|c|c|c|c|c|c|c|c|c|c|}
\hline & & $\mathrm{Ht}$ & NL & Lod & $\mathrm{AE}$ & $\mathrm{EE}$ & GN & MSW & TGW & TN & SPY & BY \\
\hline & \multicolumn{12}{|c|}{ G. PROMISE $\times$ MAZURKA $($ TT1) } \\
\hline Parental & GP & $55 \cdot 53$ & $0 \cdot 34$ & $3 \cdot 61$ & $33 \cdot 62$ & $46 \cdot 34$ & $21 \cdot 90$ & $91 \cdot 64$ & $41 \cdot 98$ & $1 \cdot 10$ & $98 \cdot 35$ & $358 \cdot 23$ \\
\hline Means & Maz & $69 \cdot 88$ & $2 \cdot 95$ & $1 \cdot 95$ & $31 \cdot 98$ & $42 \cdot 69$ & $23 \cdot 73$ & $105 \cdot 18$ & $44 \cdot 19$ & $1 \cdot 10$ & $110 \cdot 70$ & $404 \cdot 44$ \\
\hline \multirow{3}{*}{ nutans } & Mean & $67 \cdot 54$ & $1 \cdot 44$ & $4 \cdot 17$ & $33 \cdot 55$ & $44 \cdot 88$ & $22 \cdot 35$ & $103 \cdot 50$ & $46 \cdot 33$ & $1 \cdot 29$ & $126 \cdot 38$ & 393.41 \\
\hline & Min & $58 \cdot 27$ & 0.06 & 0.93 & $30 \cdot 60$ & $40 \cdot 50$ & $15 \cdot 90$ & $70 \cdot 66$ & $42 \cdot 29$ & $1 \cdot 00$ & $77 \cdot 13$ & $326 \cdot 17$ \\
\hline & $\operatorname{Max}$ & $77 \cdot 27$ & $4 \cdot 06$ & $7 \cdot 49$ & $36 \cdot 83$ & $51 \cdot 02$ & $25 \cdot 80$ & $123 \cdot 79$ & $53 \cdot 35$ & $1 \cdot 70$ & $166 \cdot 40$ & $451 \cdot 88$ \\
\hline \multirow{3}{*}{ erect } & Mean & $54 \cdot 45$ & $0 \cdot 74$ & $2 \cdot 31$ & $32 \cdot 76$ & $44 \cdot 71$ & $21 \cdot 52$ & $85 \cdot 98$ & $39 \cdot 68$ & $1 \cdot 23$ & $100 \cdot 94$ & $362 \cdot 78$ \\
\hline & Min & $48 \cdot 70$ & 0.05 & 0.86 & $30 \cdot 52$ & $40 \cdot 55$ & $16 \cdot 60$ & $62 \cdot 09$ & $35 \cdot 74$ & $1 \cdot 00$ & $65 \cdot 61$ & $282 \cdot 43$ \\
\hline & $\operatorname{Max}$ & $63 \cdot 60$ & $2 \cdot 73$ & $5 \cdot 37$ & $36 \cdot 06$ & $50 \cdot 35$ & $26 \cdot 80$ & $109 \cdot 87$ & $42 \cdot 66$ & $1 \cdot 70$ & $156 \cdot 00$ & $428 \cdot 64$ \\
\hline \multicolumn{13}{|c|}{ G. PROMISE×ARK ROYAL (TT3) } \\
\hline Parental & GP & $52 \cdot 38$ & $0 \cdot 23$ & $3 \cdot 58$ & $34 \cdot 72$ & $50 \cdot 24$ & $20 \cdot 85$ & $75 \cdot 13$ & $40 \cdot 47$ & $1 \cdot 40$ & $109 \cdot 80$ & $332 \cdot 86$ \\
\hline Means & $\mathrm{AR}$ & $67 \cdot 302$ & $0 \cdot 58$ & $5 \cdot 59$ & $40 \cdot 66$ & $54 \cdot 20$ & $22 \cdot 20$ & $92 \cdot 95$ & $41 \cdot 35$ & $1 \cdot 40$ & $112 \cdot 40$ & $382 \cdot 87$ \\
\hline \multirow{3}{*}{ nutans } & Mean & $66 \cdot 97$ & $0 \cdot 82$ & $6 \cdot 69$ & $38 \cdot 43$ & $49 \cdot 54$ & $21 \cdot 04$ & $93 \cdot 06$ & $44 \cdot 15$ & $1 \cdot 40$ & $120 \cdot 66$ & $364 \cdot 39$ \\
\hline & Min & $56 \cdot 18$ & $0 \cdot 20$ & 3.98 & $33 \cdot 58$ & $42 \cdot 39$ & $15 \cdot 30$ & $64 \cdot 16$ & $36 \cdot 89$ & 0.99 & $66 \cdot 70$ & 298.78 \\
\hline & $\operatorname{Max}$ & $73 \cdot 97$ & $2 \cdot 12$ & $9 \cdot 14$ & $45 \cdot 55$ & $60 \cdot 69$ & $25 \cdot 10$ & $118 \cdot 30$ & $50 \cdot 61$ & $2 \cdot 10$ & $176 \cdot 10$ & $419 \cdot 00$ \\
\hline \multirow{3}{*}{ erect } & Mean & $55 \cdot 01$ & 0.26 & $3 \cdot 21$ & $35 \cdot 88$ & $51 \cdot 04$ & $21 \cdot 22$ & $81 \cdot 51$ & $38 \cdot 45$ & $1 \cdot 31$ & $101 \cdot 50$ & $364 \cdot 06$ \\
\hline & Min & $46 \cdot 36$ & 0.40 & 0.82 & $33 \cdot 24$ & $45 \cdot 09$ & $17 \cdot 00$ & $59 \cdot 00$ & $32 \cdot 18$ & 0.99 & $58 \cdot 90$ & $309 \cdot 13$ \\
\hline & $\operatorname{Max}$ & $61 \cdot 00$ & 0.60 & $6 \cdot 62$ & $39 \cdot 90$ & $59 \cdot 92$ & $24 \cdot 20$ & $94 \cdot 39$ & $42 \cdot 89$ & 1.69 & $136 \cdot 80$ & $424 \cdot 31$ \\
\hline \multicolumn{13}{|c|}{ BH4/143/2 ×ARK ROYAL (TT4) } \\
\hline Parental & $\mathrm{BH} 4$ & $53 \cdot 84$ & $0 \cdot 02$ & $3 \cdot 00$ & $34 \cdot 39$ & $59 \cdot 17$ & $20 \cdot 50$ & $79 \cdot 70$ & $38 \cdot 71$ & $1 \cdot 12$ & $82 \cdot 46$ & $369 \cdot 68$ \\
\hline Means & AR & $71 \cdot 09$ & $0 \cdot 78$ & $5 \cdot 25$ & $39 \cdot 28$ & $52 \cdot 14$ & $23 \cdot 20$ & $94 \cdot 73$ & $40 \cdot 79$ & $1 \cdot 21$ & $103 \cdot 29$ & $456 \cdot 71$ \\
\hline \multirow{3}{*}{ nutans } & Mean & $65 \cdot 73$ & $0 \cdot 46$ & $5 \cdot 21$ & $38 \cdot 40$ & $52 \cdot 76$ & $19 \cdot 83$ & $83 \cdot 09$ & $42 \cdot 07$ & $1 \cdot 11$ & $89 \cdot 42$ & $381 \cdot 49$ \\
\hline & Min & $49 \cdot 23$ & 0.08 & $2 \cdot 00$ & $31 \cdot 62$ & $43 \cdot 34$ & $15 \cdot 70$ & $39 \cdot 29$ & $35 \cdot 31$ & 0.94 & $39 \cdot 37$ & $290 \cdot 43$ \\
\hline & $\operatorname{Max}$ & $75 \cdot 35$ & $2 \cdot 57$ & $7 \cdot 50$ & $46 \cdot 52$ & $61 \cdot 15$ & $24 \cdot 73$ & $105 \cdot 00$ & $49 \cdot 39$ & 1.76 & $141 \cdot 75$ & $475 \cdot 80$ \\
\hline \multirow{3}{*}{ erect } & Mean & $53 \cdot 80$ & 0.08 & $2 \cdot 17$ & $34 \cdot 98$ & $52 \cdot 15$ & $19 \cdot 95$ & $75 \cdot 24$ & $37 \cdot 76$ & $1 \cdot 11$ & $81 \cdot 38$ & $384 \cdot 84$ \\
\hline & Min & $48 \cdot 08$ & $0 \cdot 13$ & $1 \cdot 00$ & $30 \cdot 62$ & $43 \cdot 23$ & $16 \cdot 53$ & $57 \cdot 05$ & $31 \cdot 30$ & 0.96 & $58 \cdot 19$ & 317.86 \\
\hline & $\operatorname{Max}$ & $59 \cdot 96$ & 0.41 & $3 \cdot 50$ & $38 \cdot 43$ & $62 \cdot 19$ & $22 \cdot 60$ & $94 \cdot 90$ & $43 \cdot 32$ & $1 \cdot 39$ & $109 \cdot 42$ & $467 \cdot 35$ \\
\hline
\end{tabular}


Table 3(a) Results from the analyses of variance conducted on the double haploid and SSD lines produced from the TI cross

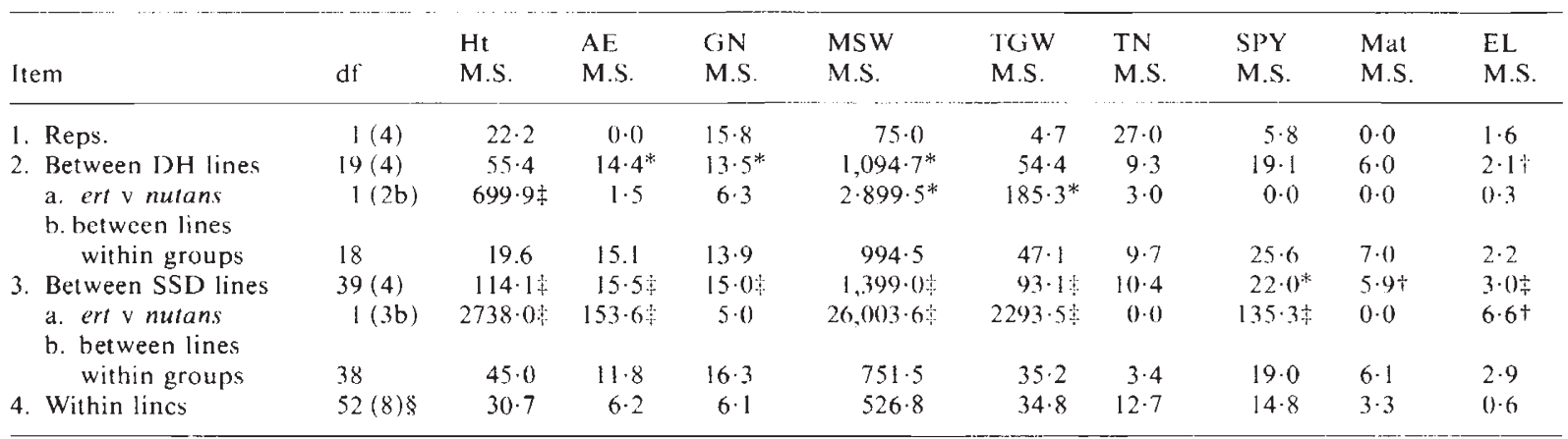

$* \mathrm{P}<0.05,+\mathrm{P}<0.01, \ddagger \mathrm{P}<0.001$.

$\S$ Indicates the number of missing plots.

( ) Indicates the crror mean square used in the V.R. test.

Table 3(b) Results from the analyses of variance conducted on the doubled haploid and SSI) lines produced from the TT3 cross

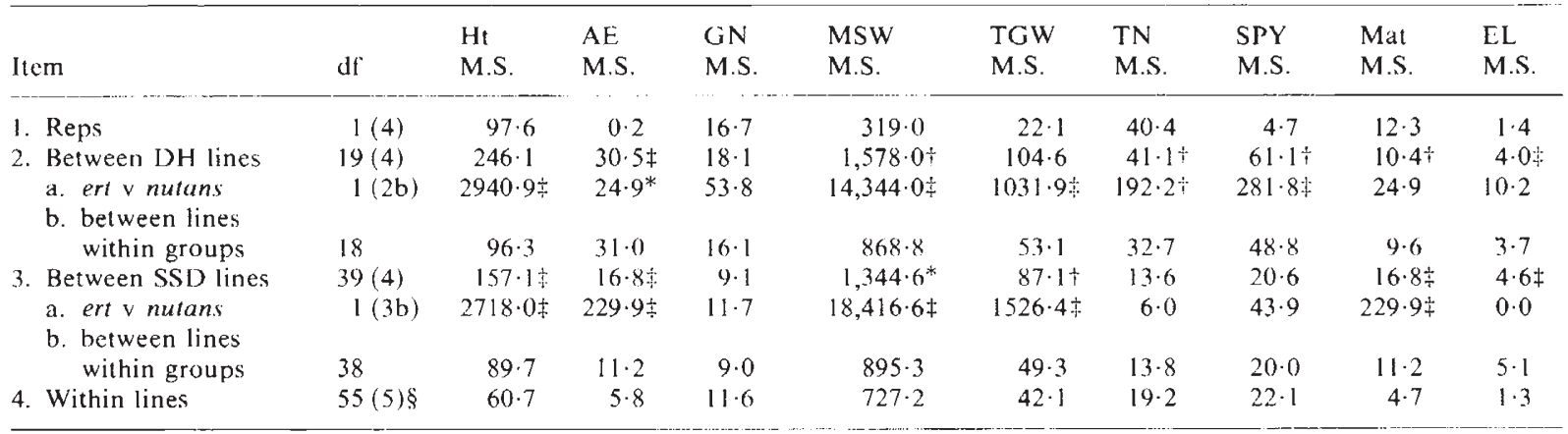

$* \mathrm{P}<0.05,+\mathrm{P}<0.01, \neq \mathrm{P}<0.001$.

$\$$ Indicates the number of missing plots.

( ) Indicates the error mean square used in the V.R. test.

Table 3(c) Results from the analyses of variance conducted on $F_{1}$ and $F_{2}$ derived doubled haploids together with SS1) lines from the TT4 cross

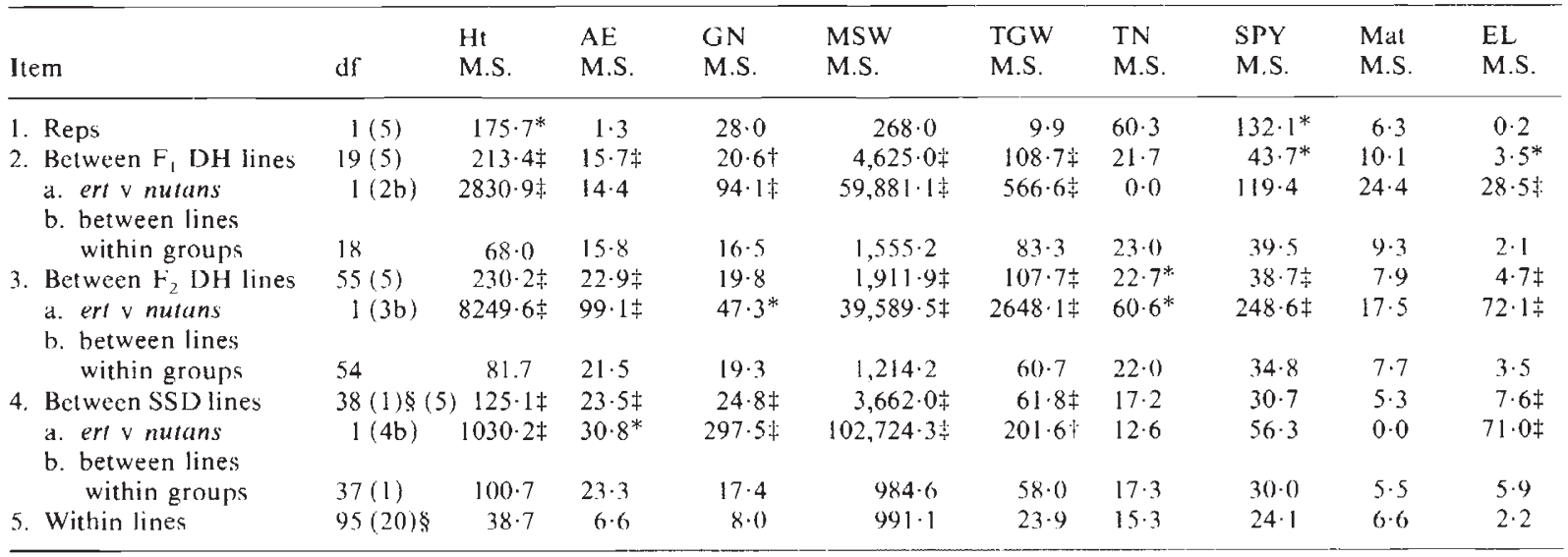

$* P<0.05, \dagger P<0.01, \neq P<0.001$.

$\$$ Indicates the number of missing plots.

( ) Indicates the error mean square used in the V.R. test. 
the erectoides group was significantly smaller than the nutans group. It is of considerable interest to note that the mean squares for the erectoides $v$. nutans item in the analyses of variance (table 1) were significant when tested against the between lines within groups item. This feature of the data is particularly important since it indicates that a significant portion of the additive variation is associated with allelic differences at the GP ert locus. This association between characters may be due to pleiotropy or linkage disequilibrium. Barley provides a unique opportunity to distinguish between these two mechanisms since populations derived by double haploidy from the Fl generation and single seed descent will differ as a consequence of the number of rounds of gametogenesis.

\section{(ii) Spaced plant experiment}

The results of the analyses of variance conducted on the data from the spaced plant experiment grown in 1983 are given in tables 3(a), 3(b), and 3 (c). The most important points to be noted from these tables are:

(a) There were significant differences between the means of the erectoides and nutans sub-populations and these differences were observed in both the DH and SSD generations.

(b) These data confirm the observation on drilled plots that a significant portion of the additive genetic variation was associated with allelic differences at the GP ert locus. The magnitude of this portion is the reduction in the additive genetic variation when it is re-estimated from the component of variance between lines within groups (Al-Banna, Jinks and Pooni, 1984).
Estimates (from the spaced plant experiment) of the total additive genetic variance $(D)$ and that associated with allelic differences at the GP ert locus for the TT1, TT3 and TT4 cross are given in table 4 . Since the SSD lines were at the $\mathrm{F}_{7}$ generation but derived from $\mathrm{F}_{4}$ single plants $\frac{7}{8} D$ was used in the estimates of $D$ from the SSD population. Where there was no significant difference between lines, the additive genetic variance was not calculated. It can be seen from this table that alleles at the GP ert locus accounted for a large part of the additive genetic variation for characters such as thousand grain weight, main stem weight and single plant yield. The lines derived by SSD from F2 individuals were bulked at the $F_{4}$ generation and have passed through 3 rounds of potential recombination and one would therefore expect a decreasing trend from $\mathrm{F}_{1} \mathrm{DH}$ (1 round of recombination) to SSD lines in the contribution of the GP ert locus to estimates of $D$ if the association is due to linkage disequilibrium. The significance of differences between estimates of $D$ associated with the GP ert locus in the DH and SSD populations can be tested by maximum likelihood model fitting procedures (Pooni, Jinks and Pooni 1980). In effect, one fits a model to the between groups and between lines within groups mean squares assuming a single value of $D$ but allowing the between lines within groups mean squares to take their own values. Since the number of lines within each subgroup was not equal, the harmonic mean was used to calculate the coefficient for the expected mean square. There is 1 degree of freedom left for testing the goodness of fit of the model in the TT1 and TT 3 cross and two degrees of freedom in the case

Table 4 Estimates of the additive genetic variance $(D)$ and that associated with allelic differences at the GP ert locus for the TTl, TT 3 and TT 4 crosses

\begin{tabular}{|c|c|c|c|c|c|c|c|c|c|c|c|}
\hline & & & $\mathrm{Ht}$ & $\mathrm{AE}$ & $G N$ & MSW & TGW & $\mathrm{TN}$ & SPY & Mat & $\mathrm{EL}$ \\
\hline \multirow{5}{*}{ TT1 } & \multirow{2}{*}{$\mathrm{F}_{1} \mathrm{DH}$} & Total $D$ & 0.0 & $4 \cdot 1$ & $3 \cdot 7$ & 284.0 & $0 \cdot 0$ & 0.0 & $0 \cdot 0$ & $0 \cdot 0$ & 0.7 \\
\hline & & GP ert & 0.0 & 0.0 & $0 \cdot 0$ & $50 \cdot 1$ & 0.0 & 0.0 & 0.0 & 0.0 & 0.0 \\
\hline & \multirow{3}{*}{ SSD } & Total $D$ & $36 \cdot 5$ & $4 \cdot 1$ & 3.9 & $381 \cdot 6$ & $25 \cdot 5$ & 0.0 & $3 \cdot 2$ & $1 \cdot 1$ & $1 \cdot 1$ \\
\hline & & GP ert & $30 \cdot 2$ & 1.7 & 0.0 & $283 \cdot 3$ & $25 \cdot 3$ & $0 \cdot 0$ & $1 \cdot 4$ & 0.0 & 0.0 \\
\hline & & $\chi_{(1)}^{2}$ & - & 0.8 & $0 \cdot 0$ & 0.5 & - & - & - & - & 0.8 \\
\hline \multirow{5}{*}{ TT3 } & \multirow{2}{*}{$\mathrm{F}_{1} \mathrm{DH}$} & Total $D$ & 92.7 & $12 \cdot 4$ & $0 \cdot 0$ & $425 \cdot 4$ & $31 \cdot 3$ & $11 \cdot 0$ & $19 \cdot 4$ & $2 \cdot 9$ & $1 \cdot 4$ \\
\hline & & GP ert & 74.9 & 0.0 & 0.0 & $359 \cdot 0$ & $25 \cdot 8$ & $4 \cdot 2$ & $6 \cdot 1$ & $0 \cdot 0$ & 0.0 \\
\hline & \multirow{3}{*}{ SSD } & Total $D$ & $42 \cdot 2$ & $4 \cdot 8$ & 0.0 & $270 \cdot 1$ & $19 \cdot 7$ & 0.0 & 0.0 & $5 \cdot 3$ & $1 \cdot 4$ \\
\hline & & GP ert & $29 \cdot 5$ & $2 \cdot 4$ & 0.0 & $196 \cdot 6$ & $16 \cdot 6$ & $0 \cdot 0$ & $0 \cdot 0$ & $2 \cdot 5$ & $0 \cdot 0$ \\
\hline & & $\chi_{(1)}^{2}$ & $0 \cdot 1$ & 0.5 & - & $0 \cdot 0$ & 0.0 & - & - & 0.5 & 1.5 \\
\hline \multirow{7}{*}{ TT 4} & \multirow{2}{*}{$\left(\mathrm{F}_{1} \mathrm{DH}\right.$} & Total $D$ & $87 \cdot 3$ & $4 \cdot 6$ & $6 \cdot 3$ & 1816.9 & $42 \cdot 4$ & 0.0 & $9 \cdot 8$ & $1 \cdot 8$ & 0.7 \\
\hline & & GP ert & $72 \cdot 7$ & 0.0 & $2 \cdot 0$ & 1534.9 & $12 \cdot 7$ & 0.0 & 0.0 & 0.0 & 0.7 \\
\hline & \multirow{2}{*}{$\mathrm{F}_{2} \mathrm{DH}$} & Total $D$ & $95 \cdot 8$ & $8 \cdot 2$ & $5 \cdot 9$ & $460 \cdot 4$ & $41 \cdot 9$ & $3 \cdot 7$ & $7 \cdot 3$ & 0.0 & $1 \cdot 3$ \\
\hline & & GP ert & $74 \cdot 4$ & 0.7 & 0.0 & $348 \cdot 9$ & $25 \cdot 5$ & 0.0 & $2 \cdot 3$ & 0.0 & 0.6 \\
\hline & \multirow{3}{*}{ SSD } & Total $D$ & $37 \cdot 8$ & $7 \cdot 4$ & $7 \cdot 4$ & $1168 \cdot 5$ & $16 \cdot 6$ & 0.0 & $2 \cdot 9$ & 0.0 & $2 \cdot 4$ \\
\hline & & GP ert & $10 \cdot 7$ & 0.1 & $3 \cdot 3$ & $1168 \cdot 5$ & $1 \cdot 7$ & 0.0 & $0 \cdot 3$ & 0.0 & 0.8 \\
\hline & & $\chi_{(2)}^{2}$ & $0 \cdot 3$ & $0 \cdot 3$ & $1 \cdot 1$ & 0.5 & $0 \cdot 5$ & -- & 0.2 & - & 0.2 \\
\hline
\end{tabular}


of the TT4 cross. Where there was no significant additive genetic variation a model was not fitted. The chi-squared $\left(\chi^{2}\right)$ values for these comparisons are also given in table 4 and apart from a border line significance in the case of ear length in the TT3 cross it can be seen that there were no significant differences between the estimates of $D$ associated with the GP ert locus from the different populations. In other words the contribution of alleles at the GP ert locus did not appear to decrease following rounds of gametogenesis.

\section{DISCUSSION}

The results presented here have a number of implications for the use of dwarfing genes in breeding programmes. First, one can only adequately estab. lish the effects of different dwarfing genes by the assessment of random inbred lines segregating for alleles at the gene locus of interest. In the three crosses examined, the mean scores of the erectoides sub-populations were lower than that of the nutans sub-populations for important agronomic characters such as: main stem weight, thousand grain weight and single plant yield. This result would suggest that the nutans group should not be a priori discarded in a breeding programme. However, the plant breeder often desires a low expression for some of the characters scored e.g., height, awn emergence and ear emergence. For these characters, the plant breeder would be better to work with the erectoides sub-population. Considering all the characters, the breeder would try to achieve a suitable balance in their expression according to his objectives.

In variety production in an inbreeding species the most important genetic component is the additive genetic variance $(D)$. This is the heritable portion of the phenotypic differences between homozygotes and is the fixable portion of the heritable variation (Mather and Jinks, 1971). Analyses of the data presented here have shown that the portion of $D$ associated with the GP ert locus can be as high as 100 per cent. Allelic variation at this locus makes a large contribution to the variation for: thousand grain weight, main stem weight and single plant yield. This association could be due to pleiotropy or linkage disequilibrium. The $\mathrm{F}_{1} \mathrm{DH}, \mathrm{F}_{2} \mathrm{DH}$ and $\mathrm{SSD}$ generations differ in respect to the number of rounds of gametogenesis that will have contributed to estimates of $D$. If the association is due to linkage disequilibrium a decreassing trend from $F_{1} D H$ to $S S D$ would be anticipated. This trend is not apparent and thus the residual effects in the SSD population could be due to pleitropy and or residual tight linkages remaining after 3 rounds of gametogenesis. AlBanna et al. (1984) working with Nicotiana rustica concluded that the pleiotropic effects of the major genes studied were not important. This would not appear to be the case with the present results and may reflect differences in the genetic architecture or the fact that the erectoides allele of Golden Promise was produced by mutagenesis and may therefore have associated with it a wider range of effects.

The major objective of most barley breeding programmes is to identify desirable recombinants. Considering table 2 , it can be seen that although the mean score of the erectoides sub-population is generally lower than that of the nutans sub-population, the best line in the erect group exceeds the higher scoring parent. Hence by deriving random inbred lines by SSD, one is able to generate erectoides high scoring lines.

There is evidence that selection for quantitatively varying characters amongst homozygous families results in an increase in selection efficiency. Since the associations between the GP ert gene and quantitative characters remained after 3 rounds of recombination in the SSD generation it would suggest that $F_{1}$ derived $D H$ lines would be equally effective in producing desirable erectoides lines.

Acknowledgements We acknowledge the technical assistance of Mr G. R. Drabble, Mr W. Wood, Mrs M. McGuigan, Mrs J. I. Gordon and $\mathrm{Mr}$ T. Nelson. We are also grateful to $\mathrm{Mr}$ M. S. Phillips for his help with some aspects of the computing. The advice and encouragement of Dr A. M. Hayter during the early stages of this work is also acknowledged.

\section{REFERENCES}

AI. BANNA, M. K. S. JINKS, J. L.. ANI) POONI, H. S. 1984. The contribution of pleiotropy at the mop loci to continuous variation in Nicotiana rustica. Heredity, 52, 95-102.

HUANC;, B., IOUNWELL, J. M., POWELL, W., HAYTER, A. M. AND $W()() 1), W .1984$. The relative efficiency of microspore culture and chromosome elimination as methods of haploid production in Hordeum vulgare L. Z. Pflanzenzucht. 92, 22-29.

MATHER, K. ANI) JINKS, J. L. 1971. Biometrical Geneties, 2 nd Edn. London: ('hapman and Hall.

POONI, H. S., IINKS, I. 1. AND POON1, G. S. 1980. A general method for the detection and estimation of additive, dominance and epistatic variation for metrical traits IV. Triple test cross analysis for normal families and their selfs. Heredity, 44, 172192.

THIOMAS, W. T. B. AND TAPSI:LA, ( . R. 1983. Cross prediction studies on spring barley. 1. Estimation of genetical and environmental control of morphological and maturity characters. Theoret. Appl. Genet., 64, 345-352.

IHOMAS, W. T. B., POWELL, W. ANI) W(O)D, W. 1984. The chromosomal location of the dwarfing gene present in the spring barley variety Golden Promise. Heredity, 53 177-183. 